\title{
Knowledge Technology Transfer: A Spatial Analysis within the Triad
}

\author{
Luigi Aldieri ${ }^{1}$, Marisa Faggini ${ }^{1} \&$ Concetto Paolo Vinci ${ }^{1}$ \\ ${ }^{1}$ Department of Economic and Statistical Sciences, University of Salerno, Italy \\ Correspondence: Luigi Aldieri, Department of Economic and Statistical Sciences, University of Salerno, Italy. \\ E-mail: laldieri@unisa.it
}

Received: May 2, 2018

Accepted: June 10, 2018

Online Published: August 1, 2018

doi:10.5539/ijbm.v13n9p89

URL: https://doi.org/10.5539/ijbm.v13n9p89

\begin{abstract}
The aim of this study is that of further exploring the knowledge spillover effects of Large International firms. In particular, we implement a spatial analysis in United States, Japan and Europe. We use technological vectors of firms to compute Jaffe proximity measure in such a way that we get knowledge externalities relative to different countries. To our end, we estimate the spatial-autoregressive model where we consider also additional endogenous variables. The findings demonstrate the significant positive effect predicted by the core literature about this topic.
\end{abstract}

Keywords: diffusion process, spatial models, productivity

\section{Introduction}

There are two relevant notions of potential Spillovers in literature (Griliches, 1979). Indeed, R\&D activities can produce knowledge spillovers and rent spillovers. The first type of Spillovers relates to new goods without taking into account the technological innovation in the price. The second type of spillovers considers the knowledge created and transferable across firms or countries (Aldieri, 2011). In this paper, we pay attention mainly to the concept of knowledge Spillovers, which does not consider the improvement in the pecuniary variables.

We find many works that analyse the technology externalities in the empirical literature. Usually, the distance between patent portfolio vectors is employed to identify proximity between the firms, inserted in a particular knowledge space (Benner \& Waldfogel, 2008).

The main objective of this work is to explore the spatial dimension of the knowledge interactions between large international firms. To this end, we introduce a spatial approach, by assuming that R\&D expenditures of each firm are affected by the expenditures of nearby firms. In this way, we can investigate the extent to which the technological proximity is sensitive to spatial perspective. Thus, our aim is to contribute to existing literature on the knowledge spillover effects of Large International firms, by developing the spatial-autoregressive model where we consider also additional endogenous variables. In particular, the analysis considers three world economic areas: the United States, Japan and Europe.

The paper (Note 1) is organized as follows. Section 2 reviews the relevant literature. Section 3 presents the data. Empirical framework is discussed in section 4 and, finally, section 5 suggests some policy implications for further research.

\section{Literature Review}

For a good assimilation of other firms' knowledge, it is important to exploit the proximity to the source of externalities, as suggested by many economists (Aldieri and Cincera, 2009; Carreira and Lopes, 2018; Jaffe, 1986; Jaffe et al., 1993; Orlando, 2004), which have explored knowledge technology flows taking into account the geographic proximity or technological linkages between the innovation producer and the recipients. In particular, Carreira and Lopes (2018) found that regional knowledge Spillovers differ substantially across industries. However, it has been recognized that both the technological and the geographical distance between firms affect knowledge flows from innovation. Indeed, different approaches have been implemented to measure technological and geographical knowledge Spillovers. Jaffe (1986 and 1988) develops an efficient approach to measure the technology externalities. Indeed, he considers a knowledge space where the firms are located and calculates the uncentered correlation coefficient as the proximity index. From three estimation models results, 
we can observe that there is a positive effect of spillover on the firm's performance. As far as the spatial approach is concerned, Pelyasov, Kuritsyna-Korsoyskaya (2009) develop a spatial analysis through the agglomerations of knowledge firms in industries, the geographic concentration of industrial R\&D and the concentration of university R\&D. Baburin and Zemtsov (2013) explore geographical aspects of innovation processes, by paying attention mainly to the role of large cities, while Aganbegyan et al. (2013) realize an investigation of spatial aspects of modernization of the real sector in Russia. Kuznetsov et al. (2015) explore the spatial resources and limitations for modernization. Crescenzi and Jaax (2017) perform an analysis of the territorial dynamics of knowledge creation.

\section{Data}

The dataset employed in the investigation is computed as in Aldieri and Vinci $(2015,2016)$. The source of firms' economic and financial features is the EU R\&D investment scoreboards editions made every year by the European Commission JRC-IPTS (scoreboards). The analysis is developed in three World economic areas: the USA, Japan and Europe. The data correspond to companies' latest published accounts. In order to maximize completeness and avoid double counting, the consolidated group accounts of ultimate parent company are used. Companies that are subsidiaries of any other company are not listed separately. Companies are matched to the registered office of country where they are located. This is the company address notified to the official company registry. It is normally the place where a company's books are kept. After an accurate cleaning procedure of raw data, we identify a sample of 625 firms for 2010 year, useful to implement a spatial analysis. In particular, we evidence the following relevant variables for the analysis: $R \& D$ expenditures (E), net sales (S), the intra-industry $\mathrm{R} \& \mathrm{D}$ flow (SR), the capital expenditures (C) and main industry sectors according to the Industrial Classification Benchmark (ICB) at the two digits level. The variables S, C, E and SR are measured in logarithmic terms in the estimation model. In order to obtain the knowledge space in which we can present the distribution of technological classes of patents for each firm, we exploit also another dataset in this investigation: the OECD, REGPAT database, January 2012 (Note 2, Note 3). This dataset includes the firms' patent applications in the European Patent Office (EPO) until December 2011. The dataset considers also the geographical features of OECD countries and Brazil, Russia, India, China and South Africa. This technical characteristic allows paying attention also to economic aspects of different countries in the world.

The process to match the companies selected from the scoreboards to the patents from REGPAT dataset is very complex because of possible mergers and acquisitions between firms. However, the procedure is well described in Aldieri and Vinci $(2015,2016)$.

\section{Spatial Analysis Procedure}

In the empirical literature, there are two approaches to deal with the spatial dependence. From one hand, there is the spatial lag model (SAR), which can be employed to investigate the existence and strength of spatial interaction. The crucial feature of spatial analysis is the spatial weight matrix, W. Their elements have the following characteristics: non-zero values outside the principal diagonal mean that there is the possible technical relation between each possible pair of units. In symmetric matrices, if $\mathrm{w}_{\mathrm{ij}}=1$ the two observed units are neighbours and $\mathrm{w}_{\mathrm{ij}}=0$ otherwise. In case of a contiguity matrix, $\mathrm{w}_{\mathrm{ij}}=\mathrm{d}_{\mathrm{ij}}$. In this approach, $\mathrm{d}$ is some measure of geographical distance between the units. Indeed, $w_{i j}=1 / d_{i j}$, where $d_{i j}$ is the distance between places $i$ and $j$. In this case, $w_{i j}$ measures the degree of the closeness. The spatial weight matrix is usually standardized to limit dependence. In a row-normalized matrix, the $(\mathrm{i}, \mathrm{j})^{\text {th }}$ element of $\widetilde{W}$ becomes $\widetilde{w}=w_{i j} / \sum q_{i}$ where $\sum q_{i}$ is the sum of the $\mathrm{i}^{\text {th }}$ row of $\widetilde{W}$. The spatial weight matrix, $\mathrm{W}$, is important to learn whether any pair of observations are neighbours. We can assume the spatial lag as a spatial weighted average of observations at neighbouring locations. In this framework, the relative model is to be estimated through maximum likelihood approach, because OLS leads to biased and inconsistent estimates (Anselin, 1988). From another hand, there is the spatial error model (SARE), where spatial dependence in the error term is assumed. Ignoring this property leads to misleading inference (Anselin, 1988). In this paper, we use the Jaffe technological proximity matrix to identify $\mathrm{d}_{\mathrm{ij}}$ in the spatial-weight matrix (W) whose non-zero off-elements $\left(\mathrm{w}_{\mathrm{ij}}\right)$ represent the degree of potential spatial interaction between ith and jth pair of locations. By assuming that knowledge vectors are treated as geographical units, we evaluate the technological proximity between different firms or locations, as in a contiguity matrix.

Table 1 display the quality of knowledge interactions between firms. In particular, as we may observe there are 383470 total relations in a range of 429 as a minimum value and 625 as a maximum value. 
Table 1. Spatial-weighting matrix

\begin{tabular}{ll}
\hline Matrix & $625 \times 625$ \\
\hline Values & \\
\hline Min & 0 \\
Min>0 & 0.0001186 \\
Mean & 0.0015974 \\
Max & 0.5384 \\
Links & \\
Total & 383470 \\
Min & 429 \\
Mean & 612.57 \\
Max & 625 \\
\hline
\end{tabular}

We focus our attention on 625 companies for 2010 year to develop the spatial analysis. Our aim is to explore whether R\&D investment by neighbour firms determines R\&D investment in observed firm, by controlling for other economic aspects. In particular, we investigate the model given from equation (1) where we include a term for both spatial error and spatial lag, and also endogenous independent variables. To this end, we implement the Spatial-autoregressive with Spatial Autoregressive Errors and Endogenous Explanatory Variables ('spivreg' routine in STATA implemented by Drukker, Prucha and Raciborski, 2013).

$$
\begin{aligned}
& y=A \pi+B \beta+\lambda W y+u \\
& u=\rho M u+\epsilon
\end{aligned}
$$

As we may see from equation (1), $\mathrm{y}$ is the dependent variable; $\mathrm{A}$ is a matrix relative to endogenous variables, and $\pi$ is the relative parameter vector; $\mathrm{B}$ is a matrix of observations on exogenous variables and $\beta$ is the corresponding parameter vector; $\mathrm{W}$ and $\mathrm{M}$ are the spatial matrices (with 0 diagonal elements); Wy and $\mathrm{Mu}$ are the vectors typically referred to as spatial lags, and $\lambda$ and $\rho$ are the relative scalar parameters; $\epsilon$ is a vector of innovations. $\mathrm{W}$ and $\mathrm{M}$ are inverse-distance spatial weighting contiguity matrices where the distances are based on Jaffe proximity measures and we assume that $\mathrm{W}=\mathrm{M}$. Table 2 evidences the findings of instrumental variable spatial models in which also possible autocorrelation of disturbances are taken into account.

However, we know that Jaffe proximity measure has been developed by observing the distribution of patent applications rather than patents' inventors. In the future, it would be interesting to test for the robustness of our main findings, by taking into account other channels of the innovation diffusion process. Through this new procedure, the technology spillovers from the inventors' mobility will be evidenced. Moreover, Jaffe technological measure is a symmetric proximity. For this reason, in the future, it is worth investigating not only symmetric proximity measures but also asymmetric ones, which take into account the vertical interactions between the firms. In this way, we could compare our results in such a way that the findings based on horizontal spillovers are distinguished from those based on vertical ones.

Table 2. Regression results

\begin{tabular}{lll}
\hline Dependent variable: $\ln \mathrm{E}_{\mathrm{t}}$ & & \\
\hline ALL & Est. & S. E ${ }^{\mathrm{a}}$. \\
\hline Ln S & $0.54^{* * *}$ & $(0.086)$ \\
Ln C & $0.12^{* *}$ & $(0.062)$ \\
Ln SR & $-0.22^{* * *}$ & $(0.045)$ \\
Lambda & $1.09^{* * *}$ & $(0.195)$ \\
$\rho$ & $0.78^{* * *}$ & $(0.165)$ \\
\hline USA & & \\
\hline Ln S & $0.50^{* * *}$ & $(0.091)$ \\
Ln C & $0.19^{* *}$ & $(0.076)$ \\
Ln SR & $-0.18^{* * *}$ & $(0.054)$ \\
Lambda & $0.72^{* * *}$ & $(0.223)$ \\
$\rho$ & 0.55 & $(0.350)$ \\
\hline JP & & \\
\hline Ln S & $0.83^{* * *}$ & $(0.181)$ \\
\hline
\end{tabular}




\begin{tabular}{lll}
\hline Ln C & 0.14 & $(0.136)$ \\
Ln SR & $-0.40^{* * *}$ & $(0.074)$ \\
Lambda & $0.70^{* * *}$ & $(0.226)$ \\
$\rho$ & 0.30 & $(0.291)$ \\
\hline EU & & \\
\hline Ln S & $0.68^{* * *}$ & $(0.151)$ \\
Ln C & 0.05 & $(0.105)$ \\
Ln SR & $-0.21^{* * *}$ & $(0.058)$ \\
Lambda & $1.02^{* * *}$ & $(0.310)$ \\
$\rho$ & 0.47 & $(0.470)$ \\
\hline
\end{tabular}

Notes. $* * *, * *$ The significance level for the coefficients is the $1 \%, 5 \%$. We include time dummies and industry dummies in the model. Endogenous variables are Ln S, Ln C, Ln SR and Instruments are their lagged values.

We can reject the null hypothesis of the parameter relative spatial lag $(\lambda=0)$. The finding that the coefficient $\lambda$ is statistically positive for all countries seems to evidence SAR dependence in innovation intensity. As far as the parameter $\rho$ is concerned, it is not significant for each country and this result could be read in the following way: there is not a significant SAR dependence in the error term. In particular, this result is in line with respect to core literature on innovation and competition (Aghion et al., 2005): the knowledge spillover effect, identified by the spatial lag parameter in the spatial analysis, is significantly positive. This finding seems to display that there is evidence of R\&D spillovers across spatially distributed firms. Thus, both the technological and spatial proximity measures are useful in the analysis of technology diffusion processes between the firms.

The analysis implemented in this study helps to verify the extent to which technological proximity is sensitive to spatial distribution of knowledge flows. However, this investigation requires further improvements. Indeed, the spatial analysis developed here does not distinguish the potential effects of R\&D activities on competitors' R\&D decisions in different sectors (Note 4). In order to obtain this finding, we should classify the forms on the basis of the main technological activity, by assuring a sufficient number of units for each technology group.

\section{Conclusions}

The main objective of this study is that of investigating the extent to which firms' innovative activity in terms of R\&D activities is sensitive to spatial dimension of knowledge flows or spillovers at the firm level. The spatial analysis considers three World economic areas: the United States, Japan, and Europe and is performed for the 2010 year. In order to control for the technological distance between the companies, we pay attention to the procedure implemented in Jaffe (1986). In particular, for each firm we identify its patent distribution portfolio, where the knowledge classes are evidenced. Once assumed that firm's patent portfolio is treated as a geographical space, we can exploit the distance between the firms or locations. Since there is heterogeneity and weak exogeneity of the independent variables, we introduce efficient econometric techniques, the combined spatial-autoregressive model in which we consider also the disturbances and the additional endogenous variables.

We might distinguish two possible consequences of outside innovation on own innovation activity. Firstly, the incentive to invest in R\&D could decrease because of the imperfect appropriability conditions. Secondly, the oligopoly condition of markets could promote the firms in such a way that they engage more in R\&D activities. In our case, the findings show that the term relative to the intra-industry R\&D (SR) is statistically negative, by confirming the competition negative effect predicted by the core literature about this topic (Aghion et al., 2005).

This result could be relevant to theory and practice in terms of policy implications. Indeed, the industrial strategy based on mergers and acquisitions process assumes an important role to deal with the knowledge externalities between the international firms.

As far as the further research is concerned, we might develop the proximity measure between the firms on the basis of the distribution of patents' inventors rather than patent applications in the computation procedure of spillovers. In this way we could test for the robustness of our main findings, by taking into account other channels of the innovation diffusion process. Through this new procedure, the technology spillovers from the inventors' mobility will be evidenced. The analysis implemented in this study helps to verify the extent to which technological proximity is sensitive to spatial distribution of knowledge flows. However, this investigation requires further improvements. Indeed, the spatial analysis developed here does not distinguish the potential effects of R\&D activities on competitors' R\&D decisions in different sectors (Note 5). In order to obtain this finding, we should classify the forms on the basis of the main technological activity, by assuring a sufficient 
number of units for each technology group.

\section{References}

Aganbegyan, A. G., Mikheeva, N. N., \& Fetisov, G. G. (2013). Modernization of the real sector of the economy: Spatial aspects. Regional Research of Russia, 3(4), 309-323. http://dx.doi.org/10.1134/S207997051401002X

Aghion, P., Bloom, N., Blundell, R., Griffith, R., \& Howitt, P. (2005). Competition and Innovation: An Inverted-U Relationship. The Quarterly Journal of Economics, 120(2), 701-728. http://dx.doi.org/10.1093/qje/120.2.701

Aldieri, L. (2011). Technological and geographical proximity effects on knowledge spillovers: Evidence from the US patent citations. Economics of Innovation and New Technology, 20(6), 597-607. http://dx.doi.org/10.1080/10438599.2011.554632

Aldieri, L., \& Cincera, M. (2009). Geographic and technological R\&D spillovers within the triad: Micro evidence from US patents. The Journal of Technology Transfer, 34(2), 196-211. http://dx.doi.org/10.1007/s10961-007-9065-8

Aldieri, L., \& Vinci, C. P. (2015). Knowledge Migration: A Cross-National Analysis. De Economist. http://dx.doi.org/10.1007/s10645-015-9269-5

Aldieri, L., \& Vinci, C. P. (2016). Technological Spillovers through a Patent Citation Analysis. International Journal of Innovation Management, 20(2). http://dx.doi.org/10.1142/S1363919616500286;

Aldieri, L., Aprile, M. C., \& Vinci, C. P. (2017). R\&D Spillovers Effects on strategic behaviour of Large International Firms during the World Financial Crisis. International Journal of Business and Management, 12(11), 141-148. http://dx.doi.org/10.5539/ijbm.v12n11p141

Anselin, L. (1988). Spatial Econometrics: Methods and Models. Kluwer Academic Publishers: Boston.

Baburin, V., \& Zemtsov, S. P. (2013). Geography of innovation processes in Russia. Vestnik Moskovskogo Universiteta, 5(5), 22-32.

Benner, M., \& Waldfogel, J. (2008). Close to you? Bias and precision in patent-based measures of technological proximity. Research Policy, 37, 1556-1567. http://dx.doi.org/10.1016/j.respol.2008.05.011.

Capron, H., \& Cincera, M. (2001). Technological competition, economic performance and strategic behavior of international firms. Brussels Economic Review, 169(169), 33-62.

Carreira C., \& Lopes, L. (2018). Regional knowledge spillovers: a firm-based analysis of non-linear effects. Regional Studies, 52(7), 948-958. http://dx.doi.org/10.1080/00343404.2017.1360484

Crescenzi, R., \& Jaax, A. (2017). Innovation in Russia: The territorial dimension. Economic Geography, 93, 66-88. http://dx.doi.org/10.1080/00130095.2016.1208532

Drukker, D. M., Prucha, I. R., \& Raciborski, R. (2013). A command for estimating spatial-autoregressive models with spatial-autoregressive disturbances and additional endogenous variables. The Stata Journal, 13(2), 287-301.

European Commission. (2011). The 2011 EU Industrial R\&D Investment Scoreboard" JRC Scientific and Technical Research series. Retrieved from http://iri.jrc.ec.europa.eu/scoreboard.html

Griliches, Z. (1979). Issues in assessing the contribution of R\&D to productivity growth. Bell Journal of Economics, 10, 92-116. http://dx.doi.org/10.2307/3003321

Jaffe, A. B. (1986). Technological opportunity and spillovers of R\&D: Evidence from firms' patents, profits and market value. American Economic Review, 76, 984-1001.

Jaffe, A. B. (1988). R\&D intensity and productivity growth. Review of Economics and Statistics, 70, 431-437.

Jaffe, A. B., Trajtenberg, M., \& Henderson, R. (1993). Geographical localization of knowledge spillovers as evidenced by patent citations. Quarterly Journal of Economics, 108(3), 577-598. http://dx.doi.org/10.2307/2118401

Kuznetsov, S., Mezhevich, N., \& Lachininskii, S. (2015). The spatial recourses and limitations of the Russian economy modernization: the example of the North-West macro region. Economy of Region, 1(3), 25-38.

Maraut, S., Dernis, H., Webb, C., Spiezia, V., \& Guellec, D. (2008). The OECD REGPAT Database: A Presentation. 
Orlando, M. J. (2004). Measuring spillovers from industrial R\&D: on the importance of geographic and technological proximity. RAND Journal of Economics, 35, 777-786. http://dx.doi.org/10.2307/1593773

Pelyasov, A. N., \& Kuritsyna-Korsoyskaya, E. N. (2009). Geographic dimension of innovation activity. Izvestiya, Akademii Nauk Seriya Geograficheskaya, 2, 8-16.

\section{Notes}

Note 1. An earlier version of this paper is available online as working paper in a repository (Munich Personal RePEc Archive) at https://mpra.ub.uni-muenchen.de/63402/

Note 2. The explanation of the methodology relative to the construction of REGPAT database can be found in Maraut, Dernis, Webb, Spieazia and Guellec (2008).

Note 3. REGPAT dataset can be downloaded by contacting Helene.DERNIS@oecd.org

Note 4. In this paper we have employed all technology sectors, because we have not a sufficient number of companies in some of them.

Note 5. In this paper we have employed all sectors, because we have a too low number of firms in some of them.

\section{Copyrights}

Copyright for this article is retained by the author(s), with first publication rights granted to the journal.

This is an open-access article distributed under the terms and conditions of the Creative Commons Attribution license (http://creativecommons.org/licenses/by/4.0/). 